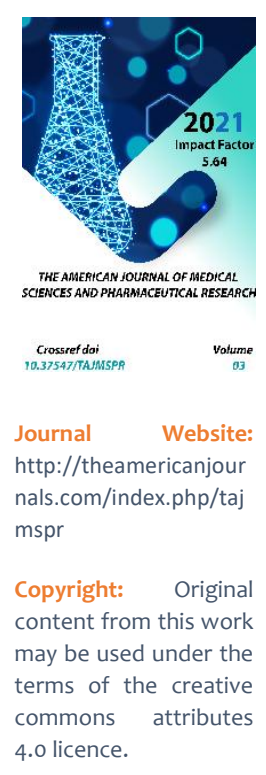

\title{
Clinical And Anamnestic Characteristics Of The Health State Of Adolescents With Vegetative Dysfunction Syndrome
}

\author{
Shadie Kurtieva \\ Center For The Development Of Vocational Qualifications Medical Workers Of The Ministry Of \\ Health Of The Republic Of Uzbekistan, Tashkent, Uzbekistan
}

\section{ABSTRACT}

The publication discusses the features of clinical and anamnestic data in adolescents with autonomic dystonia syndrome. Analysis of the health status of children and adolescents in the Youth Center of the city of Tashkent in dynamics for the period 2018-2020 testifies to the persistence of an increase in the incidence of adolescents in socially significant classes of diseases: nervous, cardiovascular, endocrine systems, accompanied by metabolic disorders, arterial hypertension. The growth rate of pathology increases in the adolescent period of ontogenesis. The psychological status of adolescents with ADS demonstrates a high frequency of disorders accompanied by high emotional instability, contributing to social and psychological maladjustment. ADS contributes to the formation of multiple organ pathology, the predominance of disharmonious and sharply disharmonious physical development, inconsistency of body mass index, impaired formation of reproductive health in adolescents with a high frequency of delayed sexual development.

\section{KEYWORDS}

Autonomic dystonia syndrome, adolescents.

\section{INTRODUCTION}

The most common non-communicable health disorder in children and adolescents is autonomic dysfunction syndrome (ADS) (ICD $X$ G90). Adolescents with ADS were assigned to the II dispensary observation group by specialists as having functional deviations in health (3). The problem of autonomic dysfunction is relevant due to the wide prevalence of this condition (up to $80 \%$ in the adolescent population), the possibility of its 
transformation into chronic diseases of the cardiovascular system $(2,5)$.

It is known that autonomic disorders are decisive in the occurrence of a breakdown of adaptive-compensatory processes, the formation of organic somatoform disorders with the involvement of almost all organs and systems in the pathological process $(5,6)$.

The autonomic nervous system maintains the constancy of the internal environment of the body (homeostasis) and autonomic support of various forms of mental and physical activity, innervation of blood and lymphatic vessels, exo- and endocrine glands and visceral organs, trophic innervation of the nervous system (CNS) and sensory organs. Therefore, autonomic disorders are decisive in the occurrence of a breakdown of adaptationcompensatory processes, the formation of organic somatoform disorders with the involvement of almost all organs and systems in the pathological process. Dysfunction of the ANS contributes to a change in all types and levels of metabolism and energy in the body, is an important pathogenetic link in the formation of most chronic diseases $(1,7,8)$.

Assessment of the functioning of the autonomic nervous system can serve as a physiological marker of the mechanisms of individual variability and response to environmental environmental factors.

\section{RESEARCH MATERIAL}

The object of the study was 243 adolescents 12-18 years old with clinically and laboratoryinstrumental confirmed dysfunction of the autonomic nervous system who were on outpatient treatment at the Teenage Center in Tashkent. The control consisted of 90 healthy adolescents matched by age and sex with the main group of the study (Table 1) Voluntary informed consent was obtained from patients and their parents to participate in the survey.

Table 1

Distribution of the surveyed by sex and age

\begin{tabular}{|c|c|c|c|}
\hline The surveyed & girls & boys & total \\
\hline $\mathrm{n}$ & 156 & 87 & 243 \\
\hline$\%$ & $64,2 \%$ & $35,8 \%$ & $100,0 \%$ \\
\hline Average age, years & $15,3 \pm 2,6$ & $14,0 \pm 2,2$ & $14,7 \pm 3,1$ \\
\hline
\end{tabular}

The average age of the clinical manifestation of SVD in girls was $12.2 \pm 1.8$ years, in boys $13.5 \pm$
2.1 years. In the group of girls, $23.7 \%(n=37)$ were prepubertal girls and $76.3 \%(n=119)$ were 
pubertal girls. In the group of boys, $28.7 \%(\mathrm{n}=$ $71.3 \%(n=87)$ were pubertal.

25) of all surveyed boys were prepubertal and
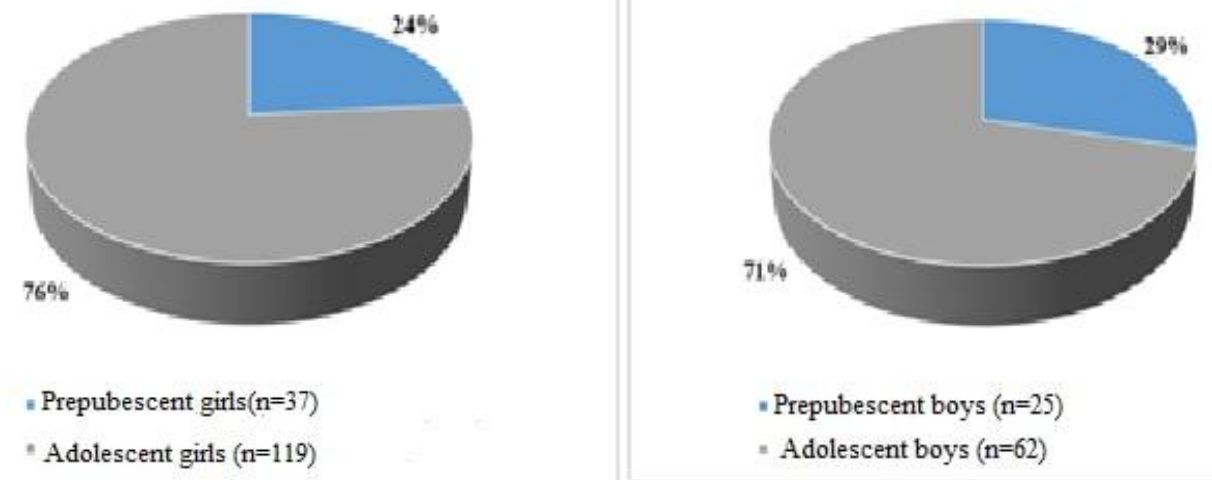

- Prepubescent boys $(\mathrm{n}=25)$

* Adolescent boys $(\mathrm{n}=62)$

Figure 1 Number of prepubertal and pubertal patients among boys and girls

Among the surveyed adolescents with ADS, there were 1.8 times less boys than girls. This is probably due to less pronounced physical and hormonal changes in the pubertal period of the development of boys, which contributed to a less pronounced manifestation of this pathology (Table 2).

Table 2 Duration of the disease in various clinical variants of ADS

\begin{tabular}{|c|c|c|}
\hline \multirow{2}{*}{ Duration of the disease } & \multicolumn{2}{|c|}{ Adolescents with ADS } \\
\cline { 2 - 3 } & Abc. & \\
\cline { 2 - 3 } Up to a year & 23 & $9,5 \%$ \\
\hline 1-3 year & 61 & $25,1 \%$ \\
\hline $3-5$ year & 86 & $35,4 \%$ \\
\hline More than 5 years & 73 & $30,0 \%$ \\
\hline Total & 243 & $100,0 \%$ \\
\hline
\end{tabular}

\section{Survey Methods}


The physical development of children was assessed according to the main anthropometric indicators (height, body weight, chest circumference) according to the generally accepted method in compliance with the requirements for them and their performance. Anamnesis data (genealogical, obstetric, life history with a list of past diseases and elucidation of possible causes of ADS) were analyzed. The initial vegetative tone (IVT) was determined using the table A.M. Wayne et al. [1981], modified for children by N.A. Belokon et al. [1987], which recorded clinical, electrophysiological and laboratory parameters. To assess autonomic reactivity, cardiointervalography (CIG) was studied, recorded in horizontal and vertical positions. To assess the vegetative support of the activity, a clino-orthostatic test (COP) is carried out (5).

Mathematical processing of the obtained data was carried out by the method of variational analysis. The mean values $(M)$ and their mean error $( \pm m)$ differences between the mean values 0$)$ were determined, the criterion of compliance $(x 2)$, the probability value $(p)$.

The relationship between the studied parameters was determined using the linear correlation coefficient $( \pm r)$. The results were considered statistically significant at $p<0.05$. The estimation of the direct correlation was considered: up to \pm 0.3 - small; from \pm 0.3 to \pm 0.7 - average; \pm 0.7 to 1.0 large.

\section{RESEARCH RESULTS AND DISCUSSION}

The assessment of the physical development of adolescents with SVD revealed the predominance of mesosomatic development in $76.2 \%$ of adolescents, macrosomia was revealed in $11 \%$ of cases. There was a high frequency of disharmonious $42.2 \%$ and sharply disharmonious physical development (RF) - in $11.6 \%$ of adolescents. In the pubertal period of development, retardation of physical development occurs with the same frequency in boys and girls (14.4\% and $16.3 \%$, respectively) (Table 3). 


\section{Indicators of physical development of children ADS $(M \pm m)$}

\begin{tabular}{|c|c|c|c|c|}
\hline Group & $\begin{array}{l}\text { Weight, } \\
\text { (kg) }\end{array}$ & Height $(\mathrm{cm})$ & $\begin{array}{c}\text { Chest } \\
\text { circumference }\end{array}$ & $\begin{array}{c}\text { Head } \\
\text { circumference }\end{array}$ \\
\hline \multirow{2}{*}{$\begin{array}{l}\text { Prepubertal girls }(n=37) \\
\text { Girls puberty }(n=119)\end{array}$} & $37,2 \pm 1,5$ & $131,2 \pm 3,6$ & $69,4 \pm 2,1$ & $54,2 \pm 0,8$ \\
\hline & $51,8 \pm 3,1^{*}$ & $163,8 \pm 2,1^{*}$ & $82,0 \pm 2,5^{*}$ & $55,6 \pm 1,3^{*}$ \\
\hline \multirow[t]{2}{*}{ Prepubertal boys $(n=25)$} & & & & \\
\hline & $39,7 \pm 1,9$ & $148,5 \pm 1,9$ & $69,9 \pm 1,7$ & $55,2 \pm 1,8$ \\
\hline \multirow[t]{2}{*}{ Boys puberty $(n=87)$} & & & & \\
\hline & $60,6 \pm 3,3^{*}$ & $174,2 \pm 2,6 *$ & $84,4 \pm 2,2 *$ & $57,4 \pm 1,4^{*}$ \\
\hline
\end{tabular}

Note: * - reliability of differences in indicators $(p<0.05)$ of age groups of the corresponding sex

Outpacing rates of physical development were noted in girls (4.5\%) and boys with markers of undifferentiated connective tissue dysplasia (8.7\%) due to their tall stature. In hypothalamic syndrome $(18.6 \%)$ - due to an increase in body mass index $(p<0.05)$
The conducted studies of the sexual development of adolescents with SVD revealed that the vast majority of prepubertal adolescents have timely rates of sexual development (SD) ( $89.5 \%$ of boys and $82.4 \%$ of girls). In the structure of violations of sexual development, delayed sexual development (DSD) prevails (Table 4).

Table 4 
Structure of sexual development disorders in adolescents with ADS (\%)

\begin{tabular}{|c|c|c|c|c|}
\hline $\begin{array}{c}\text { The structure of sexual } \\
\text { development disorders (SD) }\end{array}$ & $\begin{array}{c}\text { Girls, prepubertal } \\
(\mathrm{n}=37)\end{array}$ & $\begin{array}{l}\text { Girls, puberty } \\
\qquad(\mathrm{n}=119)\end{array}$ & $\begin{array}{c}\text { Boys, prepuberta } \\
\text { I }(n=25)\end{array}$ & $\begin{array}{l}\text { Boys, puberty } \\
\qquad(n=62)\end{array}$ \\
\hline Premature SD (PSD) & $4,4^{*}$, & $14,7^{* *}, \# \#$ & $3,5 \# \#$ & 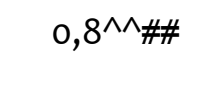 \\
\hline Delay SD (DSD) & $13,2 \# \#$ & $17,6 \# \#$ & $7,0 * * \# \#$ & $22,4 \# \#$ \\
\hline Normal SD & $82,4^{*}$ & 67,6 & $89,5^{*}$ & 76,8 \\
\hline
\end{tabular}

Note: * - $p<0.05$ in comparison, gender differences in groups;

** $-\mathrm{p}<0.001$ in comparison, gender differences in groups

$\wedge \wedge$ - $p<0.001$ differences between groups

\#\# - $\mathrm{p}<0.001$ differences versus normal

In prepubertal girls showed signs of hypoplasia of the uterus and ovaries (17.6\%) and a violation of the formation of the sexual formula - the syndrome of improper puberty (8\%). Delayed sexual development occurs 3 times more often, $p<0.05$. The number of CRD cases in boys in puberty increases 3.2 times, hypogonadism prevails in the structure of sexual development disorders (22.2\%), the absence of timely formation of secondary sexual characteristics (78.0\%).

Assessment of the initial autonomic tone makes it possible to assess the state of autonomic indicators during the period of relative rest (equilibrium of the parasympathetic and sympathetic divisions of the

ANS). An integral indicator reflecting the degree of adaptation of the organism to the disease is the stress index ( $\mathrm{TI})$. Vagotonia was determined at IU $<30$ conventional units, eutonia - IN = 30-60 conventional units, sympathicotonia - IN $>90$ conventional units. units, ID> 160 conventional units indicates hypersympathicotonic reactivity (Fig. 2). 


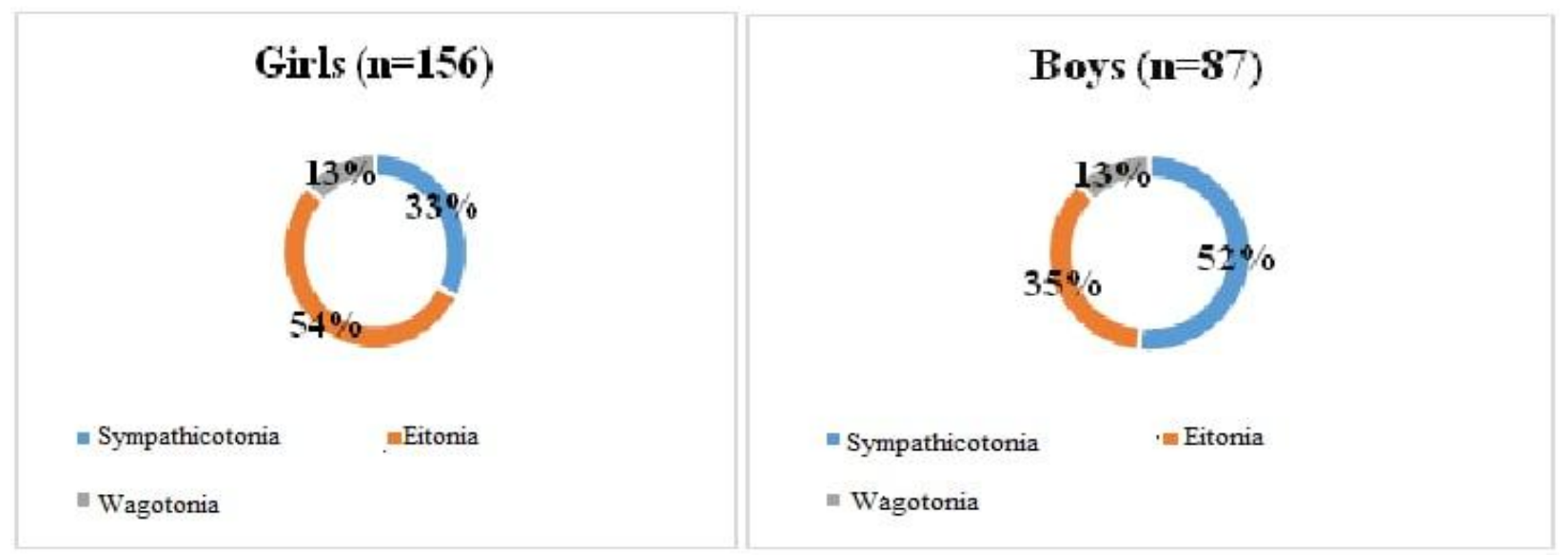

Figure 2 Initial vegetative tone in adolescents with ADS

In the study groups, there was a significantly significant difference in the number of patients with different types of VT, depending on gender. Violation of autonomic homeostasis occurred in the majority of boys' patients with an initial predominance of the tone of the sympathetic part of the autonomic nervous system in 45 patients (52\%) with hypersympathicotonic $n=62$ (71.3\%), asympathicotonic $-\mathrm{n}=16(18.4 \%)$ and normal autonomic reactivity $n=9(10.3 \%)$.

The sympathetic division of the ANS contributes to an increase in the body's performance, activation of metabolic processes in tissues, performs an energotropic function, providing the body's reserves and its active interaction with environmental factors. Excitation of the sympathetic division of the ANS occurs during a period of stress, body reactions aimed at survival (5).

In the group of girls, the predominance of the influences of the parasympathetic division of the ANS was observed. So, it was revealed in 51

patients (54\%) with sympathicotonic $-\mathrm{n}=47$ (30.1\%), asympathicotonic $-\mathrm{n}=90(57.7 \%)$ and normal $-\mathrm{n}=19$ (12.2\%) autonomic reactivity.

Sympathicotonia confirms the sufficient activity of adaptive-compensatory mechanisms in $52 \%$ of boys, which is a favorable prognostic sign in every second clinical case, which is significantly lower than this indicator in the group of girls - 32.7\% (this is only every third clinical case).

Eithonia, revealed in $13.2 \%$ of the examined ( $n$ = 32), indicates that only every fifth adolescent has a balance of regulatory sympathoadrenal and cholinergic influences. This is confirmed by the predominance in this group of a high level of normotensive autonomic reactivity of $28.3 \%$ and the minimum number of adolescents with asymptotic VR of 3.5\%. There were no significant gender differences in the study groups. 
The study of autonomic reactivity (AR) showed the predominance of hypersympathicotonic AR in most cases (62.1\%), which reflects dysadaptation associated with impaired nervous regulation, and indicates latent hypertensive reactions that contribute to the progression of arterial hypertension and ischemic heart disease in adolescents with initial vagotonia. The presence of asympathicotonic autonomic reactivity in $9.6 \%$ of adolescents indicates a pronounced imbalance of autonomic regulation and disruption of adaptive mechanisms.

Most adolescents of both gender groups had a permanent course of ADS (82.4\%). In $12.6 \%$ of girls and $5.0 \%$ of boys, a paroxysmal course was revealed, manifested by a clinic of panic attacks.

The nature of complaints in adolescents with various types of ADS is presented in Table 5 .

Table 5

Psychosomatic subjective manifestations in adolescents with ADS

\begin{tabular}{|c|c|c|c|c|}
\hline \multirow{2}{*}{ Naturre of complaints } & \multicolumn{2}{|c|}{ Girls, $\mathrm{n}=156$} & \multicolumn{2}{c|}{ Boys, $\mathrm{n}=87$} \\
\cline { 2 - 5 } & abc. & $\%$ & abc. & $\%$ \\
\hline Somatic & 126 & $56,2 \% *$ & 130 & $77,4 \%$ \\
\hline Affective & 99 & $44,2 \% *$ & 17 & $10,1 \%$ \\
\hline Neurosis-like & 120 & $53,6 \%$ & 75 & $44,6 \%$ \\
\hline Behavioral & 27 & $12,1 \% *$ & 74 & $44,0 \%$ \\
\hline Asthenic & 50 & $22,3 \% *$ & 77 & $45,8 \%$ \\
\hline
\end{tabular}

A characteristic feature was the combination of these complaints and syndromes in $72 \%$ of all patients, the monosyndromic nature of complaints was observed only in $8 \%$ of adolescents with ADS. In both study groups, a high incidence of somatic complaints, neurosis-like and affective disorders, and the severity of complaints typical of asthenic syndrome were revealed. Statistically significant differences were obtained in these clinical groups. Thus, in the group of girls, affective and neurosis-like complaints were significantly more frequent. And in the group of boys, there was a significantly high 
percentage of patients with somatic, behavioral and asthenic.

The most common clinical syndromes in patients with SVD were cephalgic syndrome (82.4\%), esophageal dyskinesia (48\%), gastric and intestinal dyskinesia (76\%), symptomatic arterial hypertension (44.5\%) and hypotension (6.2\% ), functional cardiopathy (42.4\%), neurogenic bladder dysfunction (16.5\%), vestibulopathic syndrome (12.4\%), neuroendocrine syndrome (12.2\%), neurogenic syncope (8.2\%), vegetative crises - vagoinsular (8.5\%), sympathoadrenal (2.2\%) - hyperhidrosis (5.0\%), angiotrophoneurosis (1.2\%).

Dysfunction of the cardiovascular system was manifested by blood pressure lability syndromes: orthostatic hypotension (in $4 \%$ of boys and $2.2 \%$ of girls), tachycardia at rest ( $8 \%$ and $17 \%$, respectively), symptomatic arterial hypertension ( $15.2 \%$ and $29.3 \%$, respectively). With a high frequency revealed cardialgic syndrome, characterized by "stitching" pain in the projection zone of the apex of the heart and pericardial region ( $16 \%$ and $24.2 \%$, respectively). These syndromes were detected significantly more often in sympathicotonic type AR and arterial hypertension. Electrocardiographic changes were manifested by an increase in the amplitude of the T wave (6.2\% and $8 \%$, respectively) and ST segment ( $2.2 \%$ and $6.2 \%$, respectively), sinus arrhythmia (32\% and $42.4 \%$ ), supraventricular extrasystole ( $18.4 \%$ and $23.4 \%$, respectively).

Numerous gastroenterological manifestations in ADS in the absolute majority of cases (82\%) were manifested by esophageal dyskinesia (32\% of boys and $42.4 \%$ of girls), duodenogastric reflux $(24.6 \%$ and $26 \%$, respectively), intestinal dyskinesia ( $18.2 \%$ and $18 \%$, respectively) dysfunction of the hepatobiliary tract with signs of cholestasis (32\% and 38\%, respectively).

With vagotonia, endocrine pathology was detected 3.7 times more often in boys ( $p$ $<0.05$ ), in girls - functional disorders of the gastrointestinal tract, with sympathicotonic type in boys, dysfunctions of the cardiovascular system prevailed, in girls pathology of the central nervous system, deviations from the central nervous system with a high frequency were observed in all forms of ADS.

Analysis of the structure of concomitant neurological pathology revealed that in boys 2.8 times more often markers of more severe neurological disorders were detected, such as neurogenic dysfunction of the bladder, logoneurosis, tics (4.3 times), delay and other disorders of neuropsychic development ( 1.5 times more often) $(p<0.05)$.

It was found that the activity of psychosomatic complaints is positively correlated with the average indicator of anxiety (rij $=+0.41, p<0.05$ ). Based on the results of a survey and examination of adolescents, a group of somatic symptoms was identified that most often correlate with psychosomatic-skimdistress, depression and anxiety: headache ( $\mathrm{rij}=+0.5, \mathrm{p}<0.05)$, abdominal pain (rij $=+0.6, p<0.05$ ), fatigue (rij $=+0.3, \mathrm{p}<0,05)$, increased heart rate $(\mathrm{rij}=+$ 0.4, p <0.05), "unsatisfied inspiration" (rij $=+$ $0.3, p<0.05)$. Together, they represent a 
somatovegetative symptom complex preceding the formation of a chronic disease.

The combination of psycho-vegetative and somatic manifestations, accompanied by constant emotional stress, is a reliable diagnostic sign that allows at the prenosological level to identify adolescents at risk of developing chronic psychosomatic disorders.

Table 6

Frequency of neuropsychiatric disorders in adolescents with ADS

\begin{tabular}{|c|c|c|c|c|}
\hline \multirow{2}{*}{$\begin{array}{c}\text { Markers of neurological } \\
\text { distress in ADS }\end{array}$} & \multicolumn{2}{|c|}{ Girls (n=156) } & \multicolumn{2}{c|}{ Boys ( $\mathrm{n}=57)$} \\
\cline { 2 - 5 } & abc. & $\%$ & abc. & \% \\
\hline Residual encephalopathy & 69 & 26,3 & 26,6 \\
\hline Enuresis & 4 & $1,5^{*}$ & 12 & $4,2^{*}$ \\
\hline Logoneurosis & 2 & $0,7^{*}$ & 6 & $2,0^{*}$ \\
\hline Tiki & 2 & $0,7^{*}$ & 9 & $3,1^{*}$ \\
\hline Delayed CPD & 13 & 4,9 & 19 & 6,6 \\
\hline Conduct disorders & 8 & 3 & 14 & 4,8 \\
\hline
\end{tabular}

Note * - significance of differences $p<0.05$ in gender groups.

At the same time, the specificity of emotional and personal characteristics and psychovegetative syndromes is determined by the peculiarities of the functioning of the endocrine system in the adolescent period of ontogenesis. We have established a high frequency of deviations in thyroid status in 18\% of prepubertal boys and $30 \%$ of boys with ADS, in girls - in $16 \%$ and $36 \%$ of cases, respectively. 
In the structure of thyroid dysfunction, euthyroid goiter of I and II degrees prevails (WHO, 2000), in 2\% - hypoplasia of the thyroid gland. Markers of subclinical hypothyroidism were established in $12 \%$ of cases, microcysts and thyroid nodular degeneration were detected in $2 \%$ of cases. In $12 \%$ of cases, changes in the echostructure and thyroid blood flow detected by ultrasound required differential diagnosis of iodine deficiency states, proven in $75 \%$ of cases, and autoimmune thyroiditis (15\%).

Abnormalities in thyroid status with a high frequency were combined with impaired rates of sexual development in both gender groups: $14 \%$ of boys and $8 \%$ of girls were diagnosed with delayed sexual development ( $p<0.05)$, in $4 \%$ of boys and $10 \%$ of girls, sexual development proceeded at a high rate, with ultrasound signs of the formation of cysticproliferative changes in the gonads (cysts of the epididymis and gonads, multifollicular ovaries).

Thus, the features of autonomic homeostasis were identified with a predominance of the tone of the parasympathetic autonomic nervous system, with an absolute predominance of hypersympathicotonic autonomic reactivity and a high frequency of asymptomatic AR in most of the boys studied, which indicates a high probability of progression and chronicity of vegetativevisceral pathology in this group of patients. A high degree of complication for concomitant metabolic and endocrine diseases and pathology of the cardiovascular system, the presence of behavioral disorders in adolescents with ADS forms a high-risk group for impaired formation of reproductive health during puberty.

\section{CONCLUSION}

The syndrome of autonomic dysfunction is accompanied by a high frequency of disorders in the physical development of adolescents (disharmonious physical development due to the mismatch between the mass index and the girth of the body), the predominance of the sympathicotonic orientation of the ANS activity in adolescent boys and parasympathetic orientation in adolescent girls, a higher frequency of neuropsychiatric and metabolic disorders that contribute to the early onset of arterial hypertension, neurological and endocrine pathology. The obtained results of the study will allow optimize the focus of preventive, therapeutic and diagnostic measures to improve the health of adolescents.

\section{REFERENCES}

1. Babichev, V.N. Organization and functioning of the neuroendocrine system [Text] / V. N. Babichev // Problems of endocrinology, 2013- Tashkent: 59.-№ 1.-P.62-69.

2. Vegetative dystonia in children [Text]: a guide for doctors / N. A. Korovin, T. M. Tvorogova, I. N. Zakharova, L. P. Gavryushova - Moscow:,2006, P. 67.

3. Velikanova, L.P. Clinical and epidemiological monitoring of the state of neuropsychic health of children and 
adolescents [Text] / L.P. Velikanova //

Pediatrics. - 2004. - № 1. - P. 67-70.

4. Volodin, N.N. Perinatal encephalopathy and its consequences - discussion questions of semiotics, early diagnosis and therapy [Text] / N.N. Volodin, M.I., Medvedev, S.O. Rogatkin // Russian Pediatric Journal. — 2007. - № 2. - P. 25-

28.

5. Children's vegetology. Ed. R.R. Shilyaeva, E.V. Neudakhina. Moscow: Publishing House “MEDPRACTICA-M", 2008: P. 408.

6. Neudakhin E.V. Basic concepts of vegetative dystonia syndrome in children and the principles of treatment. Pediatrician practice. 2008; 3: P. 5-10

7. Ichihara, S. The pathological roles of environmental and redox stresses in cardiovascular diseases [Text] / S. Ichihara // Environ Health Prev Med. 2013 May;18(3):177-84.

8. Kishi, T. Heart failure as an autonomic nervous system dysfunction / T. Kishi // J Cardiol. 2012 Ma;59(2):117-22. 